\title{
Evolução da Moléstia de Hansen (MH) em onze doentes com HIV+e AIDS*
}

\author{
The evolution of Hansen's Disease \\ in eleven patients with AlDS
}

\author{
Vivian Barzi Loureiro ${ }^{1}$, Caroline Coronado Cha', Beatriz Keiko \\ Zambon', Luciana Maragno², Juliana Favaro², \\ Leontina da Conceição Margarido³
}

\begin{abstract}
Loureiro VB, Cha CC, Zambon BK, Maragno L, Favaro J, Margarido L da C. Evolução da Moléstia de Hansen (MH) em onze doentes com HIV+ e AIDS. Rev Med (São Paulo). 2008 jan.-mar.;87(1):66-75.

RESUMO: A moléstia de Hansen (MH) e a AIDS são importantes problemas de saúde pública no Brasil. Este trabalho visa verificar a incidência de co-infecção pelo HIV e AIDS num grupo de doentes de hanseníase. Foram examinados 620 doentes de hanseníase, com ou sem estado reacional, no período de 1987 a 1997. Após consentimento, foram submetidos ao teste de ELISA, para HIV; os positivos foram confirmados pelo Western Blot, tratados e seguidos. Foram diagnosticados onze doentes $(1,8 \%)$ com HIV. São descritos no trabalho a evolução deste grupo de doentes quanto aos aspectos clínicos, terapêuticos, histológicos, estados reacionais e resposta ao antígeno de Mitsuda. Conclusões: 1. A técnica de Elisa para diagnóstico do HIV é segura nos doentes de $\mathrm{MH}$. 2. Os estados reacionais da $\mathrm{MH}$ não interferiram nos resultados de ELISA e de Western Blot. 3. Doentes com teste de Mitsuda positivo podem se tornar menos positivos com a imunossupressão do HIV, o que nos indica progressiva diminuição de resistência específica contra o $\mathrm{BH}$, sugerindo que o HIV e a AIDS promovem modificação da resposta imune celular específica ao $\mathrm{BH}$. 4. Provavelmente, a infecção pelo HIV pode reduzir o período de incubação da MH. 5. Doentes paucibacilares e portadores do HIV+, adequadamente tratados contra a $\mathrm{MH}$, não apresentam recidiva após a instalação da AIDS.
\end{abstract}

DESCRITORES: Hanseníase/etiologia. Hanseníase/imunologia. Hanseníase/epidemiologia. Infecções por HIV/diagnóstico. Infecções por HIV/imunologia. Síndrome de Imunodeficiência adquirida/diagnóstico. Síndrome de Imunodeficiência adquirida/imunologia. Comorbidade.

\footnotetext{
* Prêmio Monografias - XXVI COMU, 2007.

1. Acadêmico FMUSP.

2. Residente de Dermatologia HCFMUSP.

3. Prof ${ }^{a}$. Assistente Doutora, Depto Dermatologia -HCFMUSP.

Endereço para correspondência: Vivian B. Loureiro. Rua Oscar Freire, 1967, Ap. 101B. CEP: 05409-011. São Paulo, SP. e-mail: vivian_loureiro@uol.com.br
} 


\section{INTRODUÇÃO}

$\mathrm{N}$ o Brasil, a Moléstia de Hansen (MH) e a síndrome da imunodeficiência adquirida (AIDS), constituem uma co-infecção de grande importância em Saúde Pública ${ }^{15}$,

O coeficiente de prevalência da hanseníase, que em 1990 era de 18,5 por dez mil, continua alto; a taxa de detecção de casos novos também continua: em $1990=18,9$ e $1994=21,1 / \mathrm{cem}$ mil; da mesma forma, também o número absoluto de doentes registrados no período de 1975 a 1994 teve tendência crescente ${ }^{17}$. Em meados de 2003 a OMS ("World Health Organization Leprosy Elimination Project: Status Report 2003") demonstrou que o Brasil ultrapassou a Índia em número absoluto de doentes de hanseníase. O Coeficiente de prevalência na Índia foi de 3,2 doentes por 10.000 pessoas e o do Brasil 4,42 por 10.000 habitantes. Em alguns estados brasileiros esse número é maior, a exemplo de MS com 30,19 doentes por 10.000 . Os números oficiais demonstram que entre os doentes brasileiros, $51 \%$ são multibacilares (contagiantes); enquanto na Índia, apenas $36 \%$ dos doentes são multibacilares.

Em 2003, o Brasil teve 77.154 doentes novos matriculados, o que representou $85 \%$ dos doentes americanos e $16 \%$ dos doentes do mundo. Porém, há muito tempo, sabe-se que esse número representa apenas a ponta de um verdadeiro "iceberg". Em abril de 2004, o Lancet publicou os números correspondentes aos seis países mais endêmicos do mundo, demonstrando valores correspondentes a doentes infantis e multibacilares. Pode-se dizer que a moléstia de Hansen continua em franca ascensão neste País, onde predominam os doentes do grupo multibacilar ( $\pm 65 \%$ dos doentes) e onde a maioria dos doentes ainda não foi diagnosticada. A moléstia de Hansen continua predominando no sexo masculino, tendo a proporção de 2 homens/ 1 mulher.

Em relação à AIDS, a taxa de detecção de casos novos também continua importante: o total de taxa de detecção no período de 1980 a 1995 foi de 56,3/cem mil; com predomínio no sexo masculino, 5 homens/1 mulher. Neste mesmo período foram notificados 76.396 doentes de AIDS, dos quais cerca de $45 \%$ já faleceram. Têm sido relatadas a existência de coinfecções do HIV, em especial com tuberculose e em populações de alto risco para ambas as doenças ${ }^{7,9,18,19}$. Assume importância, nessas condições, a ativação de infecções latentes, como por exemplo a tuberculose pulmonar e extra-pulmonar, reativações e morte, com taxas de prevalência progressivamente aumentadas ${ }^{7,9}$. Da mesma forma, tem sido relatada a co-existência da infecção por HIV em doentes com MH MH,12,14,30,31 $^{10}$

Na moléstia de Hansen, Rotberg, $1937^{25}$ em
$1986^{26}$ demonstrou a existência de dois grupos de pessoas na população: a) o primeiro, que se constitui dos que nasceram com um Fator Natural $(\mathrm{FN})$, provavelmente genético, que Ihes confere resistência específica ao bacilo de Hansen e que abrange cerca de $80 \%$ da população. Este grupo, submetido ao Teste de Mitsuda, tem resposta positiva, caracterizada clinicamente, por pápula de 5 (+) a $10 \mathrm{~mm} \mathrm{(++)} \mathrm{ou} \geq$ com nódulo ulcerado (+++); estes indivíduos têm condições de desenvolver granuloma tuberculóide, quando estimulados pelo bacilo de Hansen $(\mathrm{BH})$. A maior positividade do teste de Mitsuda determinará resposta tuberculóide mais bem organizada e, portanto, maior capacidade de destruição de bacilos; enquanto que, os com menor positividade farão granulomas tuberculóides mais frouxos; portanto, a resposta tecidual está diretamente relacionada ao grau de imunidade celular específica, que pode ser avaliada pelo teste de Mitsuda; b) o segundo grupo - que corresponde a cerca de $20 \%$ da população, - é constituído por pessoas que não tem FN, e, portanto não respondem positivamente ao antígeno de Mitsuda; pertencem à Margem Hansen Anérgica (MHA) de Rotberg ${ }^{25}$, com Teste de Mitsuda negativo; não significando que estes, ao se infectarem, desenvolvem hanseníase: uma parte deles tem o fator de susceptibilidade para se tornarem doentes e outros, apesar de serem anérgicos ao teste de Mitsuda, não adoecem. Há que se considerar ainda a existência de um grupo com resposta duvidosa $( \pm)$ ao teste (pequena pápula de 1 a $3 \mathrm{~mm}$ ) - seriam indivíduos com FN reduzido, mas que ainda assim, conseguiriam esboçar granuloma tuberculóide. Os indivíduos com $\mathrm{FN}$ reduzido e infectados pelo $\mathrm{BH}$ desenvolvem o grupo dimorfo da hanseníase em graus variáveis; isto é, mais próximos ou mais distantes do pólo tuberculóide (Mitsuda +++).

Demonstrou-se que doentes com sorologia positiva para HIV, em diferentes estádios evolutivos, apresentam significativa diminuição do percentual de respostas clinica e histologicamente positivas ao teste de Mitsuda; essa positividade variou entre 9\% a $32 \%$, de acordo com Petri (citada por Padilha), Padilha et al. ${ }^{20}$ e Pereira Jr. et al. ${ }^{23}$. Porém, conforme já se demonstrou ${ }^{20}$, o doente com AIDS pode ter Teste de Mitsuda +. Alguns doentes infectados pelo HIV, em diferentes estádios evolutivos, continuam com a capacidade de formar granulomas tuberculóides ${ }^{20}$; o que reforça a hipótese que, em relação ao M.I., também pode ocorrer imunoeficiência específica ao bacilo de Hansen. Infere-se que doentes com HIV+ ou com AIDS e infectados pelo BH ou com moléstia de Hansen subclínica possam evoluir para hanseníase clínica, encurtando, portanto, o período de incubação, ou ainda aumentado a patogenicidade do $\mathrm{BH}^{14}$. Trabalhos experimentais em macacos demonstraram 
que a infecção pelo HIV aumenta a suscetibilidade ao $\mathrm{BH}^{3,11}$.

Alguns autores acreditam que a infecção pelo HIV é um fator de risco importante para a hanseníase ${ }^{5}$. Orege et al. ${ }^{18}$ referem que $1,8 \%$ dos 132 doentes novos de MH tinham HIV+. Em contrapartida, Munyao et al. ${ }^{16}$ afirmaram que o $\mathrm{BH}$ não atuaria como germe oportunista nos doentes infectados pelo HIV. Existe a hipótese de que o doente infectado pelo bacilo de Hansen (BH) e HIV+ pode morrer antes do $\mathrm{MH}$ se manifestar, devido ao longo tempo de multiplicação dos bacilos e a rápida progressão do HIV para a imunodeficiência ${ }^{5,22,24,31,32}$.

A hanseníase e a AIDS são neurotrópicas, sendo o HIV também linfotrópico, desde o início. A associação destas duas moléstias pode ser desastrosa para o doente, porque além da infiltração específica do nervo pelo $\mathrm{BH}$ (no sistema nervoso periférico - SNP), pode ocorrer vasculite necrotizante pelo HIV (no SNP e no central) ${ }^{13,21,22}$. Também nos países tropicais, pode haver associação com doença de Chagas, que também acomete o SNP (determinado neuropatia, geralmente subclínica) ${ }^{27}$. A neuropatia pelo HIV pode surgir antes ou durante a imunodeficiência ${ }^{21,22}$. Quanto aos episódios reacionais nos doentes com $\mathrm{MH}$ e AIDS, Blum et al. ${ }^{4}$ observaram Reação Reversa (RR) em dois doentes de hanseníase e infectados pelo HIV; consideraram não haver diferença nos surtos reacionais destes pacientes quando comparados com aqueles não infectados ou doentes pelo HIV.

\section{OBJETIVOS}

Verificar a incidência de co-infecção pelo HIV e AIDS num grupo de doentes de hanseníase. Observar a evolução deste grupo de doentes quanto aos aspectos clínicos, terapêuticos, histológicos, estados reacionais e resposta ao antígeno de Mitsuda.

\section{CASUÍSTICA E MÉTODOS}

Durante o período de 1987 a agosto de 1997, foram examinados doentes de hanseníase (em estado reacional ou não) do Núcleo Multidisciplinar e Multiprofissional de Hanseníase (NMMH) Departamento de Dermatologia - Serviço do Prof. Evandro Rivitti - Universidade de São Paulo, Brasil. Os doentes foram classificados, de acordo com os critérios estabelecidos por Ridley e Jopling e também pela OMS (pauci e multibacilares); foram tratados, em sua maioria, com as drogas recomendadas. Para a leitura do teste de Mitsuda, o NMMH utiliza os critérios dos congressos internacionais de leprologia de Madri e de Tóquio, respectivamente em 1953 e 1958: fortemente positivo (+++) - nódulo $\geq 10 \mathrm{~mm}$ e ulcerado; positivo forte (++) - pápula de 06 a $10 \mathrm{~mm}$; positivo fraco (+) - pápula de 03 a $05 \mathrm{~mm}$; duvidoso ( \pm ) - pápula de 01 a 03mm e negativo (-) - ausência de resposta.

Após informação e consentimento, foram submetidos ao teste imunoenzimático, método de ELISA, para pesquisa do HIV-1. Os doentes com sorologia positiva foram submetidos ao teste confirmatório pela técnica de Western Blot. Os doentes positivos foram tratados e seguidos, em conjunto com o Departamento de Moléstias Infecciosas.

\section{RESULTADOS}

Foram estudados 620 doentes de hanseníase: cerca de $80 \%$ multibacilares e $20 \%$ paucibacilares; $60 \%$ masculinos e $40 \%$ feminino; $61 \%$ com 25 a 45 anos. Entre os multibacilares $54 \%$ estavam em reação tipo eritema nodoso, dos quais $60 \%$ eram ENH recidivante, às vezes necrótico ulcerativo; destes, $70 \%$ ainda estavam em tratamento com multidrogaterapia e $30 \%$ em alta medicamentosa. Onze dos 620 doentes apresentaram teste para HIV positivo (ELISA e Western Blot) representando uma percentagem de $1,8 \%$. Não houve nenhum resultado falso-positivo para HIV. Dos 11 doentes com MH e HIV +, sete eram paucibacilares (MHPB) e quatro multibacilares (MHMB). Os dados de identificação dos doentes, data dos dois diagnósticos, resultado do teste de Mitsuda, da baciloscopia, início dos tratamentos e drogas utilizadas, assim como outras intercorrências.

Dois doentes paucibacilares desenvolveram AIDS após terem sido tratados para $\mathrm{MH}$ : a) um deles (doente n. 01 - H.S.S., 21 anos, branco, era homossexual, com Teste de Mitsuda fortemente +++ , foi submetido à monoterapia com sulfona, para $\mathrm{MH}$, de 1983 a 1987; nesse período desenvolveu necrose caseosa do nervo ulnar e, posteriormente, foi submetido a enxerto microneurocirúrgico com fragmentos de nervo sural. Em 1983, tinha sorologia positiva para vírus da hepatite B; em 1991 - sorologia positiva para HIV-1 - classificação da AIDS - categoria $A^{6}$ (Sistema Revisado de Classificação da infecção pelo HIV para adultos e adolescentes... ${ }^{6}$. Categoria $A=\geq 500$ cel. T-CD4/ $\mu \mathrm{l}$, HIV agudo, assintomático ou com linfoadenopatia; Categoria $B=200$ a 400 cel. T-CD4/ $\mu \mathrm{l}$, sintomático; Categoria $\mathrm{C}=\leq 200 \mathrm{cel}$. $\mathrm{T}-\mathrm{CD} 4 / \mu \mathrm{l}$ - indicador de AIDS. (CD4 $\geq 500 \mathrm{cel} / \mu \mathrm{l}){ }^{6}$; b) outro (doente n. 02, L.A.G.B., 41 anos, branco, masculino, bissexual) com teste de Mitsuda + , fez multidrogaterapia - esquema com sulfona $100 \mathrm{mg} /$ 
dia associada à rifampicina 600mg de 30/30 dias, durante pelo menos um ano, em 1990. Após a alta medicamentosa, teve neurite moderada no nervo fibular esquerdo; detectou-se sorologia positiva para HIV, em 1991, AIDS categoria A (CD4 $\geq 500 \mathrm{cel} / \mu \mathrm{l})^{6}$.

Em 1992, ao se instalar a imunossupressão, caracterizada pelas baixas taxas de CD4 (AIDS CD4 < $200 \mathrm{cel} / \mu \mathrm{l}$. - categoria $\mathrm{C}^{6}$ ) e pelas infecções secundárias habituais, os dois doentes paucibacilares acima descritos não apresentaram recidiva da hanseníase e não tiveram neurites; porém, a resposta ao Teste de Mitsuda tornou-se mais fraca: o n. 01 de +++ passou para duvidoso e o n. 02 de + passou para negativo.

Em 1995, o doente n. 03 (ASMB, 27 anos, masculino, pardo, homossexual) desenvolveu lesões clínicas de MHDT (poucas pápulas e nódulos róseos, isolados, nos membros) e tinha diagnóstico de HIV+ desde 1994; CD4=310 cel/ $\mu$ l em janeiro/1995, AIDS - categoria $\mathrm{B}^{6}$ ). Diagnóstico MHPB - teste de Mitsuda positivo $+(05 \mathrm{~mm})$, foi tratado com ofloxacin$200 \mathrm{mg} / \mathrm{dia}+$ rifampicina $-600 \mathrm{mg} / \mathrm{mês}$ associada ao AZT e Sulfamethoxazole + Trimethropin, quanto ao tratamento da AIDS. Após 4 meses (abril/95) - CD4 $=198 \mathrm{cel} / \mu \mathrm{l}$. Em novembro/95 (CD4 =205 cel $/ \mu \mathrm{l})$ foi associada DDI (di-deoxi-inosina) ao AZT. Após um mês (dezembro/95, CD4=236 cel/ $\mu \mathrm{l}$ ) houve início de Reação Reversa (RR), com dor e parestesia na base do septo nasal e na gengiva peridentária; parestesia no lado esquerdo do nariz e região medial do olho esquerdo. Um mês após, janeiro/1996, com CD4=464 $\mathrm{cel} / \mu \mathrm{l}$, surgiram novas lesões cutâneas (nódulos róseos e edematosos) e neurite com aumento do volume dos nervos fibular e tibial direito, seguido de "pie tombant", parestesias e dores na planta do pé. Comparando-se os exames histopatológicos pré e após a RR, se tornou evidente a melhor organização dos granulomas tuberculóides. Foi instituída corticoterapia com prednisona, 80mg/dia. Em fevereiro de 1996, estava recebendo $40 \mathrm{mg}$ de prednisona quando passou a receber 3TC (lamivudina) - $150 \mathrm{mg}$ de 12/12 horas, para substituir o DDI (interpretada pelo infectologista como desencadeante da neurite). Em março/96, recebendo $20 \mathrm{mg}$ de prednisona em dias alternados, estava com CD4=302 cel/ $\mu \mathrm{l}$; os sintomas neuríticos haviam remitido - não apresentava pé caído nem parestesias ou dores na planta do pé $D$. Persistia parestesia na gengiva peridentária anterior. Em agosto/1996 - CD4=245 cel/ $\mu$ l estava bem, sem lesões e sintomas do $\mathrm{MH}$ e recebendo MDT para AIDS (AZT+DDI+inibidor de protease do HIV).

A doente n. 04, MSCM, - 34 anos, fem., branca, convivia com o doente n. 10 - O.O. (MHMB, bi-sexual, usuário de drogas injetáveis). Tinha sido examinada em 1978, como contato de $\mathrm{MH}$, sem lesões cutâneas; o teste de Mitsuda foi positivo ++. Teve o diagnóstico de HIV+, Categoria $A^{6}$, em 1987 (sem lesões cutâneas); a AIDS se instalou em 1992 (categoria $\mathrm{B}^{6}$ ), quando também se diagnosticou, hanseníase paucibacilar (dimorfa tuberculóide) com placas eritematosas de relevo discreto, assimétricas, em geral, bem delimitadas e Teste de Mitsuda duvidoso (03 mm). Sorologia para citomegalovírus IgM+. Iniciou MDT-OMS para MH e AZT para AIDS. Faleceu em 1993, com as lesões cutâneas de MH em regressão; isto é, clinicamente existiam máculas hipocrômicas e no exame histopatológico se observava dermoepidermite crônica inespecífica. A doente $n$. 04 teve três gestações: a primeira filha nasceu em 1980 - viva e sadia; o segundo foi natimorto (1984); o terceiro filho nasceu em 1990 - HIV+ no primeiro mês de vida; a seguir, os exames para HIV se tornaram negativos, repetidamente. Sem lesões cutâneas de hanseníase.

O doente n. 05 (R.C.S., 13 anos, masculino, pardo, sofria abuso sexual) tinha diagnóstico de AIDS desde fevereiro de 1996. Em junho de 1996, com $\mathrm{CD} 4=08$ (categoria $\mathrm{C}^{6}$ ) em tratamento de bronquiectasia bilateral + esofagite crônica bacteriana e giardíase teve também o diagnóstico de hanseníase paucibacilar: $\mathrm{MH}$ Indeterminado - máculas hipocrômicas ou eritêmatohipocrômicas, com normoestesia ou hipoestesia térmica, predominantes na face; teste de Mitsuda positivo + (05mm). Foi tratado com DDI, AZT, Bactrim, metronidazol, sulfona e rifampicina. Em novembro, regressão da maioria das lesões.

O doente n. 06 (A.P., 59 anos, masculino, homossexual) teve diagnóstico de HIV+ em 1995, classificado na categoria C (CD4 = $152 \mathrm{cel} / \mu \mathrm{l})$ da AIDS e estava sendo tratado com AZT. Referiu aumento progressivo de manchas esbranquiçadas na pele durante cerca de seis meses. Em fevereiro/1996 com CD4= $55 \mathrm{cel} / \mu \mathrm{l}$, iniciou associação de AZT e DDI. Em maio, com CD4=126 cel/ $\mu$ l, as lesões cutâneas tornaram-se mais eritêmato-edematosas e dolorosas, com aparecimento de parestesias nas pernas e pés. Em julho (CD4=164 cel/ $\mu \mathrm{l}$ - AIDS categoria $C^{6}$ ), surto reacional intenso, que o trouxe ao hospital: tinha múltiplas placas no tórax, membros superiores e nos inferiores, raras na face, com distribuição assimétrica; a maioria bem delimitadas e duas de limites imprecisos; iniciou o tratamento com MDT-PB. O exame histológico de três placas evidenciou granulomas tuberculóides, índice baciloscópico zero. Teste de Mitsuda positivo ++. Em agosto/96 já com lesões menos inflamatórias e com leve descamação, iniciou AZT+ DDI+ 3TC. Em dezembro de 1996, a grande maioria das lesões está aplainada e violácea ou violàceo-acastanhada, com pregueamento cutâneo. Continua com parestesias nos pés, porém discretas. Respondendo bem à terapêutica 
específica (que será continuada) para enfermidade de Hansen; com CD4=14 cel/ $\mu \mathrm{l}$ e 237.000 cópias de RNA HIV-1/ml (Corning Nichols Institute), iniciou Rinovir associado ao 3TC+ AZT.

$\mathrm{O}$ doente n. $07-\mathrm{MH}$ indeterminado (curado) continua em tratamento na casa da Aids. A esposa morreu com AIDS e neuro-toxoplasmose; não soubemos se também tinha $\mathrm{MH}$.

Quatro doentes tinham MHMB (quatro dimorfos/ dimorfo-virchowianos e outro virchowiano). Os doentes n. 07 (J.G.M.) e n. 08(O.O.) iniciaram tratamento para hanseníase em 1978, abandonando-o em 1981 e em 1982, respectivamente.

Em 1978, o doente n. 08 (J.G.M., 53 anos, masculino, homossexual) iniciou monoterapia com sulfona $100 \mathrm{mg} / \mathrm{dia}$ para hanseníase paucibacilar (Teste de Mitsuda positivo+), até 1982, quando abandonou o tratamento. Em novembro de 1993, retornou com hanseníase dimorfa-virchowiana, úlceras com bordas verrucosas nas pernas (culturas para fungos e bactérias negativas), mal perfurante plantar bilateral e com HIV+ (categoria $B^{6}$ ). No exame histopatológico da mucosa nasal e de gânglio inguinal, se pode observar predominância de macrófagos vacuolizados, com bacilos de Hansen íntegros e índice baciloscópico 4+. Iniciou MDT-OMS para MH. Em junho de 1994 desenvolveu intolerância medicamentosa, quando estava associando AZT (para AIDS, agora na categoria $\mathrm{C}^{6}$ ) + MDT-OMS (para $\mathrm{MH})+$ Anfotericina $\mathrm{B}$ para neurocriptococose (NCC); suspendeu-se então, o tratamento para $\mathrm{MH}$. Continuou com NCC e iniciou fluconazol. Pneumocistose e tuberculose miliar. Em fevereiro de 1995. continuava com placas eritematosas, de limites imprecisos, relevo discreto, alopecia parcial; em geral confluentes e simétricas, no tronco, abdômen e membros. Óbito em abril de 1995.

O doente n. 09, dimorfo-dimorfo, fez MDT - OMS e os antiretrovirais, desenvolveu reação tipo I, tratada com corticosteróides e está com alta medicamentosa da $\mathrm{MH}$. Continua sob tratamento antiretroviral e evoluindo bem.

Em 1978, o doente n. 10 (O.O., 28 anos, masculino, bi-sexual, usuário de drogas injetáveis) foi matriculado com diagnóstico de hanseníase virchowiana, teste de Mitsuda negativo. Fez tratamento com sulfona $100 \mathrm{mg} /$ dia e rifampicina $600 \mathrm{mg} /$ dia (durante seis meses) e com sulfona 100 $\mathrm{mg} / \mathrm{dia}$ até 1981 , quando abandonou o tratamento. Em 1987, retornou ao Hospital com hanseníase virchowiana em atividade (M.I. íntegros), sífilis, sorologia positiva para citomegalovírus e HIV+ (categoria $\mathrm{B}^{6}$ ). Abandonou os tratamentos para $\mathrm{MH} \mathrm{e}$ HIV. Retornou em 1990, imunossuprimido, com AIDS (categoria $\mathrm{C}^{6}$ ); a morfologia das lesões cutâneas da hanseníase era semelhante à apresentada em 1978 e antes da AIDS (espessamento eritêmato-violáceo difuso, com pápulas e nódulos específicos, isolados e confluentes); porém, agora associada a nódulos róseo-eritematosos - não tendo havido piora clínica significativa. O exame histopatológico de pele e gânglio evidenciavam infiltrado granulomatoso macrofágico comum e bacilos de Hansen em grande quantidade com globias. Iniciou tratamento com AZT e MDT-OMS (multidrogaterapia - esquema terapêutico preconizado pela Organização Mundial de Saúde- OMS para MH). Desenvolveu tuberculose pulmonar e toxoplasmose. Óbito em 1991.

Em 1993, o doente n. 11 (APS., 47 anos, masculino, branco, homossexual), iniciou MDT/ multi, para hanseníase multibacilar (Teste de Mitsuda negativo -). Fez tratamento até 1995 e obteve alta. Veio para o Hospital em novembro de 1996, com história de emagrecimento há um ano com piora intensa no último mês; internado com broncopneumonia por pneumocistose, lesão troncocerebelar desmielinizante e AIDS - categoria $\mathrm{C}^{6}$ (CD4= $13 \mathrm{cel} / \mu \mathrm{l})$. Tinha sorologia positiva para sífilis (FTA Abs+ VDRL -), para citomegalovírus (IgG), hepatites A e B - (IgG), com enzimas hepáticas moderadamente aumentadas. As lesões cutâneas estavam eritêmatoacastanhadas ou hipocrômicas, ora bem delimitadas ora mal delimitadas e confluentes, com relevo discreto a moderado, em todo o tegumento; rarefação superciliar caudal e alopecia parcial nos membros; espessamento assimétrico dos nervos fibulares e bilateral dos nervos auricularis magnus, ulnaris e tibialis. Evoluiu para óbito em três semanas.

\section{DISCUSSÃO}

Há referência a resultados falsamente positivos para HIV ${ }^{1,13}$. Neste estudo, não se observou doentes com resultados falsamente positivos para HIV, confirmando trabalho de Sterne et al..$^{29}$.

Há que se salientar que no Brasil, mesmo com $80 \%$ da população com Mitsuda $+(F N)$, predominam formas multibacilares da hanseníase $( \pm 65 \%)$ e no NMMH deste Hospital eles constituem $\pm 75 \%$; nesta amostra de associação hanseníase e AIDS houve inversão da distribuição de formas da $\mathrm{MH}$ : predominaram as formas paucibacilares $(6 / 9=$ $66,7 \%)$, enquanto os multibacilares foram apenas $3 / 9(33,3 \%)$, o que pode confirmar a hipótese que o HIV ao diminuir a imunidade geral, também diminui o FN, permitindo a multiplicação de BH e evolução de possíveis infecções sub-clínicas ou de antigos portadores sãos de $\mathrm{BH}$, que também evoluiriam em menor tempo. As características clínicas e histológicas 
da $\mathrm{MH}$ dos doentes acima descritos com AIDS, não diferem das classicamente reconhecidas nos não portadores do HIV, como já se notificou ${ }^{12,31}$.

\section{Teste de Mitsuda e AIDS}

Considerando-se que nos infectados pelo HIV ou nos doentes com AIDS ocorre importante diminuição do percentual de reação positiva ao antígeno de Mitsuda ${ }^{20,23}$, os exemplos acima parecem confirmar que os infectados pelo HIV, ficam mais susceptíveis a desenvolver, até mais rapidamente, hanseníase clínica após infecção pelo bacilo de Hansen ou nos casos em que já exista doença subclínica. A resposta imunológica ao M.I. parece modificar-se no doente com AIDS ${ }^{13}$; ao contrário de algumas opiniões ${ }^{9}$, este fato encontra guarida no exemplo dos doentes n. 01, 02 e 04, que antes eram Mitsuda positivo $(+++,+$ e ++ , respectivamente) e durante a AIDS, tornaram-se reatores mais fracos: dois duvidosos \pm e um negativo). A doente $n$. 04 só evidenciou lesões cutâneas quando com resposta negativa ao Teste de Mitsuda. Doentes aidéticos, que acabaram desenvolvendo clinicamente a hanseníase, já em condições com fator $\mathrm{N}$ reduzido pela AIDS ( com MH dimorfa tuberculóide- doente n. 03), ao terem sua imunidade celular melhorada, acabam readquirindo a capacidade de reagir ao M.I. e desenvolvem granulomas tuberculóides bem organizados.

$\mathrm{O}$ doente n. 06, com AIDS, Categoria $\mathrm{C}^{6} \mathrm{e}$ história clínica de $\mathrm{MH}$ de duração de seis meses, foi diagnosticado após reação tipo I (provavelmente de reversão (RR - de melhora), pois nunca havia realizado tratamento para $\mathrm{MH}$ ), estava com lesões bem delimitadas, apesar de múltiplas, e respondeu positivamente ao teste de Mitsuda. Parece ter desenvolvido a RR quando teve sua imunidade melhorada, após terapêutica dupla de AZT e DDI.

Devido ao estudo destes doentes e da revisão de literatura ${ }^{20,23}$, pudemos observar e inferir que os com Fator N (FN) de Rotberg ${ }^{25}$ (Teste de Mitsuda+) e infectados pelo M.I., ao se tornarem imunossuprimidos pelo HIV, podem reduzir a capacidade de reagir contra o M.I., tornando-se progressivamente com teste de Mitsuda menos positivo (com evolução para hanseníase paucibacilar) ou até perder a capacidade de reagir contra o M.I, tornando-se não reatores ao antígeno (Mitsuda negativo), podendo, então, evoluir para formas contagiantes da hanseníase. Portanto, os contatos conjugais de doentes de hanseníase com HIV+ (a exemplo da doente n. 04), deveriam receber multidrogaterapia preventiva contra M.I., mesmo que previamente a resposta ao teste de Mitsuda tenha sido positiva. $\mathrm{O}$ menino com $\mathrm{CD} 4=8$ $\mathrm{cel} / \mu \mathrm{l}$ teve resposta positiva + (fraca) ao teste de
Mitsuda; infelizmente, não sabemos como era sua reação previamente à imunossupressão.

Poderíamos comparar o espectro de resposta ao teste de Mitsuda a um poço de dez metros: onde no primeiro metro estaria o grau máximo de reatividade ao M.I. (Mitsuda positivo +++, nódulo de $10 \mathrm{~mm}$ ulcerado e, portanto, grau máximo de resistência específica ou de FN de Rotberg ${ }^{25}$ ); esta positividade diminuiria progressivamente até atingir o fundo do poço - a dez metros - que corresponderia ao teste de Mitsuda negativo (grau máximo de anergia ao bacilo, MHA de Rotberg). Comparativamente, o doente ao ficar com imunossupressão, inclusive AIDS, mesmo tendo nascido com FN, poderia cair progressivamente nesse poço, mas não teria como ir além dos dez metros, quando aidético. Provavelmente por isso, o virchowiano deste grupo, que antes da AIDS já era Mitsuda negativo, continuou no grau máximo de anergia e não se tornou "hipervirchowiano".

\section{HIV+ ou AIDS e evolução da hanseníase}

Predominam as formas multibacilares $( \pm 65 \%$ dos casos) e onde a maioria dos doentes ainda não foi diagnosticada. A moléstia de Hansen continua predominando no sexo masculino, 2 homens/1 mulher. Os doentes n. 01 e n. 02 diminuíram suas respostas ao teste de Mitsuda ao se tornarem imunossuprimidos, com AIDS; mas, a despeito de agora estarem com $\mathrm{FN}$ reduzido, não reativaram a hanseníase previamente tratada; parece, portanto, que o esquema terapêutico para $\mathrm{MH}$ foi eficaz.

A doente n. 04 ao se tornar imunossuprimida pelo HIV+ (34 anos), diminuiu sua resposta ao teste de Mitsuda; antes positivo ++ e depois duvidoso; como seu companheiro, doente n. 08 - O.O., abandonara o tratamento para $\mathrm{MH}$ em 1981, ao se tornar imunodeprimido também teve aumento do índice baciloscópico de bacilos de Hansen; provavelmente, essa maior carga bacilar contaminou mais a companheira, que, agora, também infectada pelo HIV e com seu Fator Natural (Mitsuda ++) progressivamente reduzido, permitiu que a infecção evoluísse para doença dimorfa tuberculóide. Porém, apesar da imunossupressão, ela ainda conseguia expressar o seu FN de oferecer resistência ao M.I., (apesar de reduzido - Teste de Mitsuda duvidoso, $03 \mathrm{~mm}$ ). e desenvolveu resposta à presença do M.I., mas com esboço de granuloma tuberculóide e BAAR 1+ no exame histológico da pele (MHDT). Morreu com as lesões de hanseníase regredidas, após o tratamento específico para $\mathrm{MH}$.

Souza Lima et al. ${ }^{28}$ demonstraram que os doentes indeterminados com teste Mitsuda positivo evoluíam mais rapidamente para manifestações do 
MH paucibacilar (em até 4 anos) que os com respostas negativas ao teste para as formas multibacilares (em geral, demoravam 5 ou 7 anos para evoluírem). Os doentes n. 03, 04, 05 e 06 apresentaram evolução da moléstia em menor tempo, pois antes da imunossupressão não tinham lesões cutâneas. A despeito da imunossupressão, responderam bem à multidrogaterapia para $\mathrm{MH}$.

Três doentes com MHMB (dois dimorfovirchowianos (doente n. 07 e 09) e outro virchowiana (doente n. 08)), já tinham estes diagnósticos anos antes da comprovação da infecção pelo HIV+. Em especial, o doente virchowiano, nos chamou atenção, porque ao contrário do que se imaginava, não piorou a micobacteriose de Hansen ao se tornar imunossuprimido pelo HIV; portanto, não apresentou significativa piora do quadro clínico-dermatológico da hanseníase após a instalação da imunossupressão aidética.

O doente virchowiano tinha teste de Mitsuda negativo em 1978, quando do seu diagnóstico do MH; isto é, pertencia à Margem Hansen Anérgica (MHA) de Rotberg 25,26 - ou seja, anergia ao Mycobacterium leprae (M.I.), provavelmente genética. Portanto, este doente, com imunossupressão específica ao M.I. e com fator de susceptibilidade ao bacilo de Hansen, desenvolveu MHVV. Ora, após também se infectar pelo HIV, mesmo tendo recebido a insuficiente monoterapia com sulfona durante 4 anos, acabou reativando a hanseníase, porém, não em grau mais acentuado ou também com maior anergia ao M.I., pois, a nosso ver, em relação ao bacilo de Hansen este doente não tinha mais o que piorar especificamente. Previamente à AIDS, ele já tinha grau máximo de anergia (resposta negativa ao antígeno de Mitsuda, ou seja, imunossupressão específica) ao M.I.

\section{Reação tipo I}

3.1. Reação reversa da hanseníase + AIDS $x$ neurite e evolução de ambas

O doente n. 03 (ASMB) com MHPB, recebeu quinolona + RFM, porque tinha um tio com MHMB que fazia tratamento irregular, e,pensou-se na possibilidade de bacilos resistentes à sulfona. Em dezembro de $1995-(C D 4=236 \mathrm{cel} / \mu \mathrm{l})$, quando da associação de DDI ao AZT, o doente iniciou reação reversa, provavelmente por três motivos: 1 . diminuiu a quantidade de vírus "HIV" circulantes; 2. também diminuiu a quantidade de bacilos de Hansen; 3. consequentemente, houve melhora da imunidade celular. Como este doente tinha Fator Natural (FN) de Rotberg, isto é, tinha Teste de Mitsuda positivo + , quando houve melhora da imunidade, inciou-se o processo de melhora da resposta granulomatosa, que se acentuou mais ainda, quando o esquema terapêutico incluiu o uso de 3TC, e então se desenvolveu granuloma tuberculóide completo, inclusive com células gigantes de Langhans; clinicamente surgiram nódulos, tipo sarcoídeos, com intensa neurite dos nervos fibular e tibial esquerdo - sensitiva e motora (pé caído); teste de Mitsuda tornou-se positivo+++, ulcerado e CD4= $464 \mathrm{cel} / \mu \mathrm{l}$.

No doente acima, descartou-se a possibilidade de neurite pelo HIV ou pelas medicações contra o HIV, porque o acometimento do sistema nervoso periférico pelo retrovirus ou pelas drogas antivirais costuma ser classificada como polineuropatia crônica inflamatória, simétrica, sensitiva e motora. $E$, além disso, nesta situação, o teste de Mitsuda não teria melhorado de + para +++ (ulcerado), com conseqüente melhor organização do granuloma tuberculóide. Sabe-se que o DDI pode induzir neuropatia periférico - que decorre de dose cumulativa-, porém, costuma ser simétrica nas extremidades, ou seja, polineuropatia. Por outro lado, o DDI isoladamente não promoveria a melhora da resposta ao teste de Mitsuda e maior organização do granuloma tuberculóide.

O doente n. 06 (AP), referiu manchas esbranquiçadas durante seis meses (CD4=55 cel/ $\mu l)$. Após três meses da associação de AZT e 3TC houve aumento do CD4 para $160 \mathrm{cel} / \mu \mathrm{l}$, quando o doente teve processo reacional agudo, com neurites, provavelmente reação reversa, devido à melhora do CD4 ( de 55 para160 agosto/96) e apesar da ausência de tratamento específico para a moléstia de Hansen. Foi classificado como MHTT subpolar, com granulomas tuberculóides bem formados, após reação tipo I, teste de Mitsuda positivo ++ (não ulcerado) + AIDS, categoria $\mathrm{C}^{6}$. Parece que a moléstia de Hansen evoluiu silenciosa e mais rapidamente neste doente já imunodeprimido, que deveria ter sido reator forte ao antígeno de Mitsuda, mas tornou-se menos competente frente ao bacilo de Hansen durante a fase de poucas células $T$-com $+/-$ CD4=55 cel $/ \mu \mathrm{l}$, voltando a destruir melhor os $\mathrm{BH}$ quando também houve aumento do CD4. Miller ${ }^{14}$ previa que doentes com $\mathrm{HIV}$ + ou poderiam encurtar $\mathrm{O}$ tempo de evolução ou a penetrância do $\mathrm{BH}$; em nossa opinião, o BH se multiplicou mais rapidamente devido à redução do $\mathrm{FN}$ de resistência específica ao $\mathrm{BH}$ que deve ocorrer quando começa haver redução das células T-CD4; neste doente, a piora imunológica e hansenológica se deu lentamente, mas talvez, se os linfócitos $\mathrm{T}$ forem reduzidos de maneira rápida, possa surgir reação tipo I-degradação; pois ao contrário, quando ocorre melhora do status imunológico, ocorre reação tipo I - de melhora. 
4. (Relapse) Recidiva ou atividade progressiva da hanseníase

Os doentes 07 e 08, com história prévia de moléstia de Hansen e abandono precoce do tratamento, tiveram evidente recidiva ou manutenção da atividade progressiva (com M.I. íntegros) do $\mathrm{MH}$ quando da imunossupressão. Talvez, indivíduos da MHA (teste de Mitsuda negativo) sem hanseníase clínica prévia e portadores de M.I., por os tolerarem, ao se tornarem imunodeprimidos, não tenham tempo para que a hanseníase se manifeste plenamente; ou ainda, diante das tantas intercorrências, a $\mathrm{MH}$ passe despercebida ou diagnosticada como outra micobacteriose.

\section{Tratamento da hanseníase}

Há quem recomende o tratamento preventivo de doentes infectados pelo HIV com PPD+; com esta conduta, se conseguiu reduzir a incidência de tuberculose de $10 \%$ para $1,7 \%$ dessa associação por ano ${ }^{19}$. Também se poderia administrar o BCG nesse grupo de risco. Optou-se pelo esquema de multidrogaterapia (sulfona (DDS) + - rifampicina (RFM)) e MDT-MB, durante período maior que o preconizado pela OMS. Esta decisão terapêutica prendeu-se à experiência dos autores no tratamento das intercorrências em doentes transplantados renais (imunossupressão induzida por medicações) - que em geral, demoram mais para ficarem curados das infecções associadas. A exemplo do doente n. 08, existem relatos dessa tríplice associação: AIDS, $\mathrm{MH}$ e tuberculose pulmonar².

\section{CONCLUSÃO}

1.A técnica sorológica pelo método Elisa para diagnóstico do HIV é segura nos doentes de Hanseníase;

1.1 O Teste de HIV foi positivo em onze doentes, ou seja, 1,8 \% dos doentes: sete homens (três bisexuais e 6 homossexuais [um também usuário de drogas]; um menino e uma mulher heterossexual com parceiro fixo $(\mathrm{MH}$ e HIV+).

2. Os estados reacionais da hanseníase, tanto tipo I como tipo II, em nossa casuística, não interferiram no resultado do teste ELISA para HIV, como também no Teste de Western Blot;

3. Doentes com teste de Mitsuda positivo podem se tornar menos positivos com a imunossupressão. A redução do teste de Mitsuda, após a infecção pelo HIV e instalação da AIDS, nos permite inferir que ocorre progressiva diminuição do Fator Natural (FN) de Rotberg ${ }^{25}$, de resistência específica contra o $\mathrm{BH}$, possivelmente até a sua negativação. Portanto, parece que o HIV e a AIDS promovem modificação da resposta imune celular específica ao $\mathrm{BH}$;

4. Provavelmente, a infecção pelo HIV pode reduzir o período de incubação da $\mathrm{MH}$ ou permitir que a doença subclínica evolua mais rapidamente;

5. Doentes paucibacilares e portadores do HIV+, adequadamente tratados contra a hanseníase (MDT perdurando, pelo menos um ano), não apresentam recidiva após a instalação da AIDS. Doentes paucibacilares com AIDS podem desenvolver reação reversa $(\mathrm{RR})$ quando ocorre melhora da imunidade celular, provavelmente, após diminuição do número de M.I. e aumento do número de células CD4/ $\mu$ l. Por outro lado, pode-se inferir que doentes de hanseníase, virgens de tratamento, com medicação irregular ou ainda com resistência às drogas e com AIDS, ao se tornarem mais imunodeprimidos, provavelmente, podem sofrer RI de degradação. Neste estudo apenas um doente (n. 03) apresentou neurite grave, com paralisia muscular importante e "pé caído" durante reação reversa $(R R)$, também caracterizada pelo aumento da resposta ao antígeno de Mitsuda (+++ com nódulo ulcerado), melhor organização dos granulomas tuberculóides da pele. No doente n. 06 as neurites dos membros inferiores foram menos intensas e consistiam principalmente de formigamentos, não tendo havido "pie tombant"; por isso, neste doente, não introduzimos corticoterapia. A corticoterapia, usada para o tratamento da neurite que acompanha a RR hansênica, foi eficaz; o doente n. 03 não ficou com paralisia e reduziu pouco a melhora do CD4 observada pela associação de medicamentos antivirais (AZT+ DDI e depois, AZT+3TC). O doente continua evoluindo bem da AIDS e sem atividade da $\mathrm{MH}$;

6. O doente virchowiano da margem Hansen anérgica (com este diagnostico previamente à infecção pelo HIV), ao contrário do que se imaginava, não piorou a micobacteriose de Hansen ao se tornar imunossuprimido pelo HIV, porque já tinha Mitsuda negativo previamente (grau máximo de anergia ao bacilo); e parece não haver condições para se tornar mais negativo;

7. Doentes com HIV+e história de tratamento prévio para hanseníase multibacilar, em especial os com índice baciloscópico $\geq 4$ ou companheiros de doentes de hanseníase, deveriam receber, quando do diagnóstico de HIV+, novo período de MDT (talvez com novas drogas) para prevenir recidiva da moléstia de Hansen. 
Loureiro VB, Cha CC, Zambon BK, Maragno L, Favaro J, Margarido L da C. The evolution of Hansen's Disease in eleven patients with AIDS. Rev Med (São Paulo). 2008 jan.-mar.;87(1):6675.

\begin{abstract}
S: The Hansen's Disease (HD) and AIDS are important problems of public health in Brazil. This work aims to verify the incidence of co-infection for HIV and AIDS in a group of patients with Hansen's disease. 620 sick people of Hansen's disease were examined, with or without reactional state, in the period from 1987 to 1997. After assent, they were submitted to the ELISA test, for HIV; the positives were confirmed by the Western Blot, treated and followed. Eleven sick people (1.8\%) with HIV were diagnosed. This work describes the evolution of this group of sick people, the clinical, therapeutical and histologic aspects, the reactional states and the reply to the antigen of Mitsuda. Conclusions: 1. The technique of Elisa for diagnosis of the HIV is safe to the HD patients. 2. The reactional states of the HD did not interfered with the result of ELISA and Western Blot. 3. Patients with positive Mitsuda test can become less positive with the immunosuppression of the HIV, what indicates gradual reduction of specific resistance against the Hansen's Bacil, suggesting that the HIV and the AIDS promote modification of the specific cellular resistance to the Bacil. 4. Probably, the infection of the HIV can reduce the incubation period of the HD. 5. Paucibacilar patients and carriers of the HIV+, adequately treated against the HD, do not present recidivation after the installation of the AIDS.
\end{abstract}

KEY WORDS: Leprosy/etiology. Leprosy/immunology. Leprosy/epidemiology. HIV Infections/ diagnosis. HIV Infections/imunology. Acquired Immunodeficiency Syndrome/diagnosis. Acquired Immunodeficiency Syndrome/immunology. Comorbidity.

\title{
REFERÊNCIAS
}

1. Andrade VL, Avelleira JC, Marques A, Vianna FR, Schchter M. Leprosy as cause of false positive results in serological assays for the detection of antibodies to HIV-1. Int J Lepr. 1991;59:125-6.

2. Arora VK, Johri A. Reactivation of tuberculosis and leprosy in a HIV positive case. Tuber Lung Dis. 1994;75:237-8.

3. Baskin GB, Gormus BJ, Martin LN, Murphey-Corb M, Walsh GP, Meyers WM. Pathology of dual Mycobacterium leprae and simian immunedeficiency virus infection in rhesus monkeys. Int J Lepr. 1990;58:358-64.

4. Blum I, Flageul B, Sow $S$, Launois $P$, Vignon-Pennamen $M D$, Coll A, et al. Leprosy reversal reation in HIV positive patients. Int J Lepr. 1993;61:214-7.

5. Borgdorff MW, van-den-Broek J, Chum HJ, Klokke AH, Graf $\mathrm{P}$, Barongo LR, et al. HIV-1 infection as a risk factor for leprosy; a case-control study in Tanzania. Int J Lepr. 1993;61:610-3.

6. Centers for Diseases Control and Prevention (CDC). National Center for Infectious Diseases. Atlanta, EEUU. 1993. Revised classification system for HIV infection ad expanded surveillance case definition for AIDS among adolescents and adults. MMWR. Morb Mortal Wkly Rep. 1992;41:n.o RR-17.

7. Desormeaux J, Johnson M, Coberly JS, Losikoff JE, Huebner R, Geiter L, et al. Widespread HIV counseling and testing linked to a community-based tuberculosis control program in a high-risk population. Bul PAHO. 1996;30.

8. Frommel D, Tekle HR, Berhe N, Aussel L, Verdier M, Preux PM. A survey of antibodies to hepatitis $C$ virus in Ethiopia. Am J Trop Med Hyg. 1993;49:435-9.

9. Garcia MLG, Gomes JLV, Sancho MCG, Alvarez RAS,
Zacarias F, Amor JS. Epidemiology of AIDS and tuberculosis. Bul PAHO. 1995;29:37-58.

10. Goodless DR, Viciana AL, Pardo RJ, Ruiz P. Borderline tuberculoid Hansen's disease in AIDS. J Am Acad Dermatol. 1994;30(5, pt.2):866-9.

11. Gormus BJ, Murphey-Corb M, Martin LN. Interactions between simian immunedeficiency virus infection in rhesus monkeys. J Infect Dis. 1990;160:405-13.

12. Jayasheela M, Sharma RN, Sekar B, Thyagarajan SP. HIV infection amongst leprosy patients in south India. Indian J Lepr. 1994;66:429-33.

13. Lucas $S$. Human immunodeficiency virus and leprosy. Lepr Rev. 1993;64:97-103.

14. Miller RA. Leprosy and AIDS: a review of the literature and speculations on the impact of CD4 lymphocyte depletion on immunity to Mycobacterium leprae. Int $\mathrm{J}$ Lepr. 1991;59:639-44.

15. Ministério da Saúde - Programa Nacional de Doenças Sexualmente Transmissíveis/AIDS. AIDS - Bol Epidemiol. 1995;7:2-31.

16. Munyao TM, Bwayo JJ, Owili DM, Ndinya-achola JO, Kwasa TO, Kreiss JK. Human immunodeficiency virus-1 in leprosy patients attending Kenyatta National Hospital, Nairobi. East Afr Med J. 1994;71:490-2.

17. Nogueira W, Marziliak MLC, Gonçalves OSJ, Brasil MTLRF. Perspectivas de eliminação da hanseníase. Hansen Int. 1995;20:19-28.

18. Orege PA, Fine PE, Lucas SB, Obura M, Okelo C, Okuku $P$, Were $M$. A case control study on human immunodeficiency virus-1 (HIV-1) infection as a risk factor for tuberculosis and leprosy in western Kenya. Tuber Lung Dis. 1993;74:377-81.

19. Pape JE, Jean SS, Ho JL, Hafner A, Johnson Jr W. 
Effect of isoniazid prophylaxis on incidence of active tuberculosis and progression of HIV infection. Lancet. 1993;34:262-8.

20. Padilha MH, Michalany NS, Rotta O. Avaliação clínica e histológica da reação de Mitsuda em indivíduos soropositivos para o vírus da imunodeficiência humana (HIV). Ann Bras Dermatol. 1995;70:295-300.

21. Parry GJ. Peripheral neuropathies associated with human immunodeficiency virus infection. Ann Neurol. 1988. Suppl.23:S49-S53.

22. Patki AH. Some possible interactions of M.I. and HIV in the periferal nerves. Int J Lepr. 1991;59:331-2.

23. Pereira JR AC, Caneschi JRT, Azulay MM, Trope BM, Avé BAC, Carneiro SCS, et al. O estudo da resposta imune em pacientes com infecção pelo vírus da imunodeficiência human (HIV) em relação ao teste de Mitsuda. An Bras Dermatol. 1992;67:97-102.

24. Ponnighaus JM, Mwanjasi LJ, Fine PEM, Shaw M-A, Turner AC, Oxborrow SM, et al. Is HIV infection a risk factor for leprosy?. Int J Lepr. 1991;59:221-8.

25. Rotberg A. Some aspects of immunity in leprosy and their importance in epidemiology, pathogenesis and classification of forms of the disease. Rev Bras Lepr. 1937;5:45-97.

26. Rotberg A. The "Hansen anergic fringe". Acta Leprol. 1986;4:347-54.

27. Said G. Infective neuropathies. Curr Opin Neurol. 1994;7:398-401.

28. Souza Lima L, Alayon FL. Sobre a significação patológica das lesões incaracterísticas (maculares simples). São Paulo: Empresa Gráfica da "Revista dos Tribunais"; 1941.

29. Sterne JA, Turner AC, Fine PE, Parry JV, Lucas SB, Ponnighaus JM, et al. Testing for antibody to human immunodeficiency virus type 1 in a population in which mycobacterial diseases are endemic. J Infect Dis. 1995;172:543-6.

30. Turk JM, Rees RJW. Aids and leprosy [editorial]. Lepr Rev. 1988;59:193-4.

31. Vreeburg AE. Clinical observations on leprosy patients with HIV1 infection in Zambia. Lepr Rev. 1992;63:13440.

32. World Health Organization. UNDF - World Bank, Kenia, 1987. Tropical diseases and HIV infection. Lepr Rev. 1988;59:267. 